\title{
Tobacco smoking and COVID-19 infection: A summary of facts from scientific literature
}

Aryal UR ID

Umesh Raj Aryal, Senior Researcher, Public Health and Environmental Research Center, Lalitpur, Nepal.

\begin{abstract}
The objective of the study is to summarise the association between COVID-19 and smoking published in peer-reviewed journals, preprint in MedRxiv /Qeios, news, and report. The literature search was conducted between $1^{\text {st }}$ to $20^{\text {th }}$ August 2020 using three databases (PubMed, Google Scholar, and Google) with the keywords "Tobacco smoking and COVID-19" as search terms. A French study claimed that smoking is a protective agent for COVID-19 infection. A meta-analysis revealed that tobacco smoking is significantly associated with COVID-19 infection. Despite the controversy surrounding the connection between smoking and COVID-19, people should not smoke or use any tobacco products because smoking is associated with increased rates of severe COVID-19.
\end{abstract}

Key words: COVID-19; Tobacco Smoking

\section{INTRODUCTION}

robacco smoking is a well-known risk factor for many

Non-Communicable Diseases (NCDs) including cardiovascular diseases, cancer, chronic lung diseases, and diabetics ${ }^{1}$. Recent data revealed that these diseases are the most prevalent comorbidities of COVID-19 (Scientific name: SARS-COV-2) for admission in the intensive care unit, mechanical ventilation, and deaths ${ }^{2-6}$. However, the lack of evidence and controversial findings have raised doubts about the connection between tobacco use and COVID-19 infection. For example, one of the studies described both obesity and tobacco smoking

Access this article online

Website: www.jkmc.com.np

DOI: https://doi.org/10.3126/jkmc.v9i4.38098

HOW TO CITE

Aryal UR. Tobacco smoking and COVID-19 infection: A summary of facts from scientific literature. J Kathmandu Med Coll. 2020;9(4):219-23.

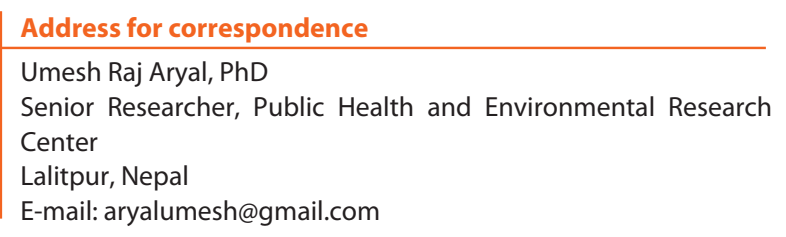

Copyright $\odot 2020$ Journal of Kathmandu Medical College (JKMC) ISSN: 2019-1785 (Print), 2091-1793 (Online)

(7) (8) This work is licensed under a Creative Commons Attribution-Non Commercial 4.0 International License. as controversial risk factors for COVID-19 infections. This study has revealed obesity, air pollution, and smoking are associated risk factors with underlying pathophysiology related to the renin angiotensin system (RAS) in COVID-19 infection ${ }^{7}$. Such a relationship has generated a lot of research interest in the scientific community. They have published several articles to explore the connection between smoking and COVID-19. To date, there are a limited number of review studies that have presented the findings of an association between smoking and COVID-19 infection ${ }^{2-7}$. Therefore, this study aimed to explore the evidence of an association between tobaccosmoking and COVID-19 infection from literature.

\section{METHODOLOGY}

The literature search was conducted between $1^{\text {st }}$ to $20^{\text {th }}$ August 2020 using three databases (PubMed, Google Scholar, and Google) with the search terms:COVID-19," OR "SARS-COV-2," AND "smoking, " OR"tobacco ".

Both peer-reviewed and preprints publications including news and reports were reviewed and included in the study. The preprint articles are complete preliminary reports of work but unpublished manuscripts in medical, clinical, and health sciences, available in MedRxiv (pronounce as "Med-Archive") ${ }^{8}$. The author also included preprint articles available in Qeios (Open Peer Review) ${ }^{9}$. One of the advantages of these two archives is that anyone can publish without peer review and later get constructive comments from the scientific community. The articles published only in English language were 
included in the study. Next, news and reports published in reputed media were reviewed and included in the study. The data showing the prevalence of tobacco use among COVID-19 patients and the relationship between tobacco smoking and COVID-19 or SARS-COV-2 were included in the study. The reference articles (cited by the authors) were also reviewed wherever required.

The inclusion criteria include: any patients with COVID-19 (survivor or deaths) with the history of smoking.,and patients who are admitted to any type of hospital care (Intensive care unit or non-intensive care unit).

Study types: Observational, cross-sectional, case-control, \& cohort studies were included comparing patients who smoke with those who do not smoke.

The exclusion criteria include i. non-English language; \& ii. any incomplete or missing data or text in the papers.

The following data were collected from all studies: Author's name, title, publication month and year, country of study, sample size, history of smoking, the status of COVID-19 (severe or not), and dead or alive.

\section{BODY}

A French study claimed that nicotine is a potential protective agent against COVID-19 infection ${ }^{10}$. They found that the current daily smoking rate was $6.1 \%$ $(\mathrm{N}=139)$ and $14 \%(\mathrm{~N}=343)$ for COVID-19 outpatients and inpatients respectively. They compared these rates with the daily smoking rate $(25.4 \%)$ of the French general population. They reported age-sex standardised incidence rate of smoking (SIR) was 0.23 (95\% Cl:0.110.25 ) and 0.23 (0.14-0.39) for COVID- 19 outpatient and inpatient respectively ${ }^{10}$. There is no statistically significant difference in SIR in the two groups (inpatient vs. outpatient). The SIR was 0.16 (0.05-0.49) and 0.30 (0.13-0.72) in the healthcare workers and others. Finally, they concluded a lower infection rate in COVID-19 patients who smoked compared to the French general population who smoked. ${ }^{10}$

A match cohort study from Israel showed that the current (OR: 0.45 (95\% Cl:0.41-0.51)) and past smokers (OR:0.81(95\% Cl:0.73-0.91)) were at a lower risk of COVID-1911. The same study also reported current (1.27 (95\%Cl:0.93-1.74)) and past smoking (0.81(0.49-1.29)) behavior is not associated with COVID-19 after adjusting age, sex, and ethnicity ${ }^{11}$.

A meta-analysis of 19 peer-reviewed scientific papers with 11,590 COVID-19 patients, concluded that smoking increases the risk of disease progression almost twice among those who smoke compared to those who do not smoke (OR:1.91, 95\% Cl:1.42-2.59) ${ }^{12}$. Another metaanalysis of 6515 patients concluded current smokers were more likely to have an adverse outcome than non-smokers (OR: 1.53, 95\% Cl: 1.06-2.20) but less likely compared with former smokers (OR: $0.42,95 \% \mathrm{Cl}$ : $0.27-$ $0.74)^{13}$. A living rapid review revealed that the mortality rate is higher among former smokers compared to never smokers (RR:1.92(1.32-2.65)) $)^{14}$. However, the mortality rate for current smokers is not statistically significant compared to never smokers (RR:1.89 (0.78-3.37) $)^{14}$. The disease severity is higher among ever smokers compared to never smokers (RR:1.43 (1.15-1.77)) ${ }^{14}$. The occurrence of the SAR-COV-2 is less likely among current smokers compared to former smokers (RR:0.74(0.56-0.97)) but it is not significant for former smokers vs. never smokers (RR:1.06(0.94-1.2)) $)^{14}$.

A recent US study revealed that there is an inverse relationship between current daily smoking prevalence and COVID-19 for both hot (-0.78, $\mathrm{P}=0.0002)$ and cold countries $(R=-0.57, P=0.0046)^{15}$. The study also reported that for each percentage point increase in the smoking rate, mortality decreased by 0.147 per 100,000 population ${ }^{15}$. The review of 174 studies described there is uncertainty about the relationship between smoking and COVID-19 and decreased risk of COVID-19 infection among current smokers ${ }^{15}$.

The study from China showed that the history of smoking behavior is associated with the disease progression $(\mathrm{OR}=14.28 ; 95 \% \mathrm{Cl}: 1.58-25.0)^{16}$. A rapid systematic review and meta-analysis explained current smokers were more likely to have severe complications compared to former and never smokers $(R R=1.45,(1.03-2.04))^{17}$. This study showed $22 \%$ of current smokers and $46 \%$ of ex-smokers had severe complications and $38.5 \%$ of current smokers died $^{17}$. Zhou et al. showed that the current smokers were two times more likely to die in the hospital compared to the non-smokers (OR: 2.23, $(0.65-7.6)^{18}$. This retrospective study also showed that there is no significant difference in the proportion of smokers who survived vs. those who did not survive ( $4 \%$ vs. $9 \%, \mathrm{P}=0.20)^{18}$. Next, the secondary data analysis of 140 COVID-19 patients with disease severity described that there is no difference in the proportion of smoking between non-severe and severe patients $(3.7 \% \text { vs. } 10 \%, \mathrm{P}=0.16)^{19}$. The result is also similar for both past smokers (3.7\% vs $6.9 \%, p=0.17$ ) and current smokers $(0 \% \text { vs } 3.7 \%, p=0.17)^{19}$.

A cross-sectional secondary data analysis of 236,439 patients showed 89,756 (23\%) had COVID-19 and 8.3\% 
of them were current smokers ${ }^{20}$. Further, the researchers applied two multivariate regression models on factors associated with COVID-19: i) treating each comorbidity separately; \& ii) Combining all comorbidity as a single variable. Both regression models showed current smokers were $23 \%$ less likely to be diagnosed with COVID-19 in all types of patients (OR: 0.77 (95\%Cl:0.740.80). They also compared current smoking behavior among hospitalised COVID-19 patients and their adverse outcomes. They reported that smoking behavior is not statistically significant in both cases (Hospitalization: 0.94(95\% Cl: 0.85-1.04), adverse outcome: 1.02 (0.881.18) $)^{20}$.

\section{DISCUSSION}

This review showed that there is both positive and negative association between tobacco smoking and COVID-19 infection. All these studies have several strengths, sampling bias, underestimations, poor quality data, and limitations $s^{1,12}$. Here are some examples from the studies: i) A large retrospective study from Mexico has presented factors associated with COVID-19 based on laboratory diagnostic, hospitalization, and adverse outcome ${ }^{20}$. This study is a valuable asset not only for Mexico but also for the low- and middle-income countries (LMICs). However, this study is not free from the limitations. Some of the limitations are that researchers were unable to use more detailed clinical and laboratory information for the patients, no detailed information available for the pharmacotherapy of comorbidities and clinical conditions of patients with comorbidities ${ }^{20}$. ii) A meta-analysis revealed smoking is significantly associated with COVID-19 infection. Though it is the highest level of research, it also has several limitations i.e. there is variation in the definition of smoking, smoking prevalence rate varies from country to country may misclassify smoking population into the non-smoking population, most of the studies have unadjusted odds ratio, and e-cigarettes were not included in the study. iii) French study showed those who smoke were at lower risk of COVID-19 infection ${ }^{10}$. The reviewer had explored the biases and weakness related to this study i.e. majority of study patients are health care workers who smoked less, the study area has low smoking rate compared to the national average, severe cases who admitted to hospital were excluded, ex-smokers were excluded and presence of social desirability bias ${ }^{10}$.

The majority of papers reviewed in this study were from high-income countries (HICS). However, more than $80 \%$ of tobacco users live in LMICs and projected to 1 billion deaths related to tobacco use at the end of the $21^{\text {st }}$ Century ${ }^{21}$. It is reported that more than $90 \%$ of COVID-19 deaths are in HICs and the remaining are from $\mathrm{LMICs}^{22}$. There is a difference in the demographic profile of COVID-19 patients between LMICs and HICs. In LMICs, much younger and older people live in their homes while in HICs older people live in nursing homes ${ }^{22}$. Nearly half of all these deaths occurred in nursing homes in rich countries ${ }^{22}$. Further, demographic data reveals that the case-fatality rates (CFR) for HICs are higher than LMICs. For example, John Hopkins University data showed that CFR for Italy, UK, USA, India, and Sri-Lanka was 13.9\%, 12.8\%, $3.1 \%, 1.9 \%$, and $1 \%$ respectively.(data updated on 18 Aug 2020 at 3 AM EDT) ${ }^{23}$. To date, there is no information available on tobacco-specific CFR for COVID-19 in both $\mathrm{HICs}$ and $\mathrm{LMICs}^{23}$. Despite the higher number of smokers who live in LMICs, there is limited information available on the link between tobacco use and COVID-19 infection and deaths. All these data suggested that there is an inverse relationship between COVID-19 deaths and the prevalence of smoking but further research is required to prove it. Further, to fulfill the gap, between HICs and LMICs the researchers need to collaborate to strengthen the research capacity for the prevention and control of viruses. Such collaboration provides opportunities to create new knowledge and enhance the impact of research by exploring existing knowledge quickly and at all levels and risk management ${ }^{24}$.

Practically, it is hard to conduct a randomised control trial or prospective studies due to the rapid spread of the virus $^{25}$. Most of the studies are cross-sectional including observational or case-series with limited data from the hospital. Therefore, A well-defined population-based prospective study is recommended for establishing a cause-effect relationship between smoking and COVID-19 with adjustments for underlying risk factors, rigorous exclusion, and a larger sample size ${ }^{25,26}$.

The majority of reports related to smoking and COVID-19 were non-peer-reviewed articles published in Qeios and MedRxiv ${ }^{7,8}$. These publications were in the preliminary stage and preprint repositories with an open peerreviewed model. However, these publications have many benefits to the scientific community to explore and generate new ideas and fill the gaps in a short period. Many reputed organizations and journals do not accept non-peer-reviewed articles. For example, recently, WHO reviewed the only peer-reviewed publications and concluded that tobacco smoking is associated with increased severity of diseases and deaths in hospitalised COVID-19 patients'. Therefore, peer-reviewed publications are highly recommended to establish the 
facts. Further, researchers needed to compare the impact of peer- and non-peer-reviewed articles.

The WHO and CDC have already developed standard tools for data collection such as Global Youth Tobacco Survey (GYTS), Global Adult Tobacco Survey (GATS) to correlate tobacco use with different socio-economic factors, and behavioral factors ${ }^{27,28}$. These tools have high reliability and have been used in many countries. In the same way, there is a need to develop standard tools for the data collection on COVID-19 infection from the demographic characteristics to the outcomes of treatment. A standard tool has reliability, validity, objectivity, easy communication, and norms that help to compute standard scores and percentiles ${ }^{29}$.

None of the studies in this review had discussed the relationship between smokeless tobacco and COVID-19 infection. However, the blog published in BMJ /Tobacco has - highlighted the importance of smokeless tobacco products on COVID-19 infection30. South Africa has already banned selling tobacco products ${ }^{31}$. India has

\section{REFERENCES}

1. WHO. Smoking and COVID-19 [Internet]. Geneva;WHO;2020 [cited 2020 Sep 8]. Available from: $\quad$ https://www.who.int/news-room/ commentaries/detail/smoking-and-covid-19.

2. Huang C, Wang Y, Li X, Ren L, Zhao J, Hu Y, et al. Clinical features of patients infected with 2019 novel coronavirus in Wuhan, China. Lancet. 2020 Feb;395(10223):497-506. [PubMed | FullText | DOI]

3. Tadic M, Cuspidi C, Sala C. COVID-19 and diabetes: Is there enough evidence?. J Clin Hypertens. 2020 May;22(6):943-48. [PubMed | FullText | DOI]

4. Guo T, Fan Y, Chen M, Wu X, Zhang L, He T, et al. Cardiovascular Implications of Fatal Outcomes of Patients with Coronavirus Disease 2019 (COVID-19). JAMA Cardiol. 2020;5(7):811-8. [PubMed | FullText | DOI]

5. Huang I, Lim MA, Pranata R. Diabetes mellitus is associated with increased mortality and severity of disease in COVID-19 pneumonia - A systematic review, meta-analysis, and meta-regression: Diabetes and COVID-19. Diabetes Metab Syndr. 2020;14(4):395-403. [PubMed | FullText | DOI]

6. Pranata R, Lim MA, Huang I, Raharjo SB, Lukito AA. Hypertension is associated with increased mortality and severity of disease in COVID-19 pneumonia: A systematic review, meta-analysis, and meta- banned the use of smokeless products and spitting in public places during COVID-1932.

\section{LIMITATIONS OF REVIEWS}

Since there are variations in data from countries to countries in terms of the study population, sample size, and outcome of the study, the direct comparison between these studies was not possible. The paper published between $1^{\text {st }}$ to $20^{\text {th }}$ August 2020 was included in the study, which may not represent the entire study. There might be the possibility of missing the publications while gathering the data.

\section{CONCLUSION}

The findings suggested that further studies are required to confirm any link between tobacco and the treatment of COVID-19 infection. Unless we obtain conclusive results, people should not smoke or use any tobacco products because smoking is associated with increased rates of severe COVID-19 infection.

\section{Conflict of Interest: None}

regression. J Renin Angiotensin Aldosterone Syst. 2020: 21(2):1-11. [PubMed | FullText | DOI]

7. Engin $A B$, Engin $E D$, Engin $A$. Two important controversial risk factors in SARS-CoV-2 infection: Obesity and smoking. Environ Toxicol and Pharmacol.2020 Aug;78:103411. [PubMed | FullText |DOI]

8. MedRxiv. The preprint server for health sciences. MedRxiv;2020[cited 2020 Aug 22]. Available from: https://www.medrxiv.org.

9. Qeios. Posting Policy. Qeios; 2020 [cited 2020 Aug 22]. Available from: https://www.qeios.com/ posting-policy.

10. Gilmore A. Review of: "Low incidence of daily active tobacco smoking in patients with symptomatic COVID-19." Qeios 2020. [FullText | DOI].

11. Israel A, Feldhamer I, Lahad A, Levin-Zamir D, Lavie G. Smoking and the risk of COVID-19 in a large observational population study. medRxiv. 2020 Jun; 20118877. [FullText]

12. Patanavanich R, Glantz SA. Smoking is Associated with COVID-19 Progression: A meta-analysis. Nicotine Tob Res. 2020;22(9):1653-56. [PubMed | FullText | DOI

13. Farsalinos K, Barbouni A, Poulas K, Polosa R, Caponnetto P, Niaura R. Current smoking, former smoking, and adverse outcome among 
hospitalised COVID-19 patients: A systematic review and meta-analysis. TherAdv Chronic Dis 2020;11:2040622320935765. [PubMed | FullText | DOI]

14. Simons D, Shahab L, Brown J, Perski O. The association of smoking status with SARS-CoV-2 infection, hospitalization, and mortality from COVID-19: A living evidence review.Qeios.2020 Aug. [FullText | DOI]

15. Norden MJ, Avery DH, Norden JG, Haynor DR. National Smoking Rates Correlate Inversely with COVID-19 Mortality. medRxiv. 2020 Jan. [FullText]

16. Liu W, Tao ZW, Wang L, Yuan ML, Liu K, Zhou L, et al. Analysis of factors associated with disease outcomes in hospitalised patients with 2019 novel coronavirus disease. Chin Med J (Engl). 2020 Feb.2020;133(9);1032-8. [PubMed | FullText | DOI]

17. Alqahtani JS, Oyelade $T$, Aldhahir AM, Alghamdi SM, Almehmadi M, Alqahtani AS, et al. Prevalence, severity, and mortality associated with COPD and smoking in patients with COVID-19: A rapid systematic review and meta-analysis. PLoS One. 2020; 15(5):e0233147. [PubMed | DOI]

18. Zhou F, Yu T, Du R, Fan G, Liu Y, Liu Z, et al. Clinical course and risk factors for mortality of adult inpatients with COVID-19 in Wuhan, China: a retrospective cohort study. Lancet. 2020;15(5): e0233147. [PubMed | DOI]

19. Zhang JJ, Dong X, Cao YY, Yuan YD, Yang YB, Yan YQ, et al. Clinical characteristics of 140 patients infected with SARS-CoV-2 in Wuhan, China. Allergy.2020; 75(7):1730-41. [PubMed | FullText | DOI]

20. Giannouchos T, Sussman R, Mier JM, Poulas K, Farsalinos K. Characteristics and risk factors for COVID-19 diagnosis and adverse outcomes in Mexico: an analysis of 89,756 laboratory-confirmed COVID-19 cases. Eur Respir J.2020;2002144. [FullText | $\mathrm{DOI}]$

21. Yach D, Pratt A, Glynn TJ, Reddy KS. Research to stop tobacco deaths. Global Health. 2014;10:39.[PubMed | FullText | DOI]

22. Cash R, Patel V. Has COVID-19 subverted global health?. Lancet. 2020;395(10238):1687-8. [PubMed | FullText | DOI]

23. John Hopkins Corona Resource Center. Mortality Analysis[Internet].United States of America: John Hopkins Corona Resource Center;2020.[cited 2020 Aug 19]. Available from: https://coronavirus.jhu. edu/data/mortality.
24. World Economic Forum.COVID-19: Collaboration is the engine of global science - especially for developing countries[Internet]. World Economic Forum;2020[cited 2020 Aug 20]. Available from: https://www.weforum.org/agenda/2020/05/globalscience-collaboration-open-source-covid-19.

25. Zhao Q, Meng M, Kumar R, Wu Y, Huang J, Lian N, Deng $Y$, Lin $S$. The impact of COPD and smoking history on the severity of COVID-19: A systemic review and meta-analysis. J Med Virol. 2020 Oct;92(10):1915-21. [PubMed | FullText | DOI]

26. Zheng Z, Peng F, Xu B, Zhao J, Liu H, Peng J et al. Risk factors of critical \& mortal COVID-19 cases: A systematic literature review and meta-analysis. J Infect.2020;81(2): e16-25. [PubMed | FullText | DOI]

27. WHO. Global youth tobacco survey(GYTS)[Internet]. Geneva:WHO;2020. [Cited 2020 Aug 21]. Available from:https://www.who.int/tobacco/surveillance/ gyts/en/.

28. CDC. Global adult tobacco survey(GATS) [Internet].Atlanta: CDC;2020. [Cited 2020 Aug 21]. Available from:https://nccd.cdc. gov/GTSSDataSurveyResources/Ancillary/ Documentation.aspx?SUID=4\&DOCT $=1$.

29. Sauro J. Advantages of standardised usability questionnaires[Internet]. Denver: Measuring U;2020. [cited on 2020 Aug 21]. Available from:https:// measuringu.com/standardised-usability/.

30. Hefler M. Smokeless tobacco use and the COVID-19 pandemic. Blog|Tobacco Control[Internet]. 2020 March 30 [cited 2020 Aug 20].Available from:https:// blogs.bmj.com/tc/2020/03/30/smokeless-tobaccouse-and-the-covid-19-pandemic/.

31. The Washington Post. Virus ban gives tobacco illegal drug status in South Africa [Internet]. The Washington Post; July 2020[cited 2020 Aug 20]. Available from:https://www.washingtonpost.com/ world/africa/ban-gives-tobacco-illegal-drug-statusin-south-africa/2020/07/02/ad3c2256-bc31-11ea97c1-6cf116ffe26c_story.html.

32. The Economic Times. 28 states, UTs ban smokeless tobacco products, spitting due to Coronavirus[Internet]. India: The Economic Times; May 2020 [cited 2020 Aug 20]. Available from:https://economictimes.indiatimes.com/news/ politics-and-nation/28-states-uts-ban-smokelesstobacco-products-spitting-due-to-coronavirus/ articleshow/75657382.cms. 